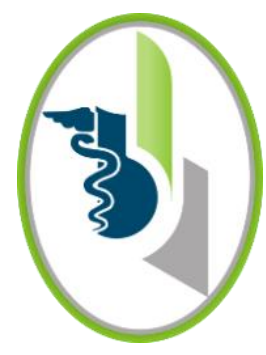

ACCESO $\odot$ ABIERTO

Para citaciones: Perez, Z., Pereira, G., Díaz, A. (2020). Rol bacteriano en la gingivitis ulcero necrotizante aguda. Revista Ciencias Biomédicas, 9(1), 7173.

Recibido: 16 de septiembre de 2019 Aprobado: 27 de noviembre de 2019

Autor de correspondencia:

Zara Pérez-Quiñones

zperezq@unicartagena.edu.co

Editor: Inés Benedetti. Universidad de Cartagena-Colombia.

Copyright: (C) 2020. Perez, Z., Pereira, G., Díaz, A. Este es un artículo de acceso abierto, distribuido bajo los términos de la licencia https://creativecommons.org/licenses/bync-sa/4.0/ la cual permite el uso sin restricciones, distribución y reproducción en cualquier medio, siempre y cuando el original, el autor y la fuente sean acreditados.

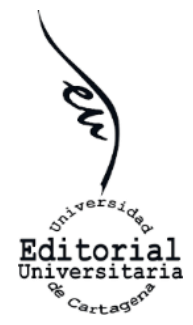

\section{Rol bacteriano en la gingivitis ulcero necrotizante aguda}

\author{
Bacterial role in acute necrotizing ulcer gingivitis
}

\author{
Zara Pérez-Quiñones ${ }^{1}$ (D), Geilyn Pereira-Morales ${ }^{2}$ (D), Antonio Díaz-Caballero ${ }^{3}$ (ic \\ ${ }^{1}$ Grupo de investigación GITOUC, Cartagena, Colombia. \\ ${ }^{2}$ Semillero de investigación GITOUC. Facultad de Odontología, Universidad de Cartagena, Colombia. \\ ${ }^{3}$ Facultad de Odontología, Grupo de investigación GITOUC, Universidad de Cartagena, Colombia.
}

\section{Resumen}

La gingivitis ulcero necrotizante aguda (GUNA) es una enfermedad infecciosa del tejido gingival que se presenta comúnmente como una inflamación y/o ulceración aguda y dolorosa. A pesar de ser una infección de origen bacteriano, aún existe cierto grado de confusión con respecto a las bacterias asociadas a ella y a la función que cumplen en el progreso de la patología. Este ensayo busca establecer una posición epistemológica con relación al papel que juegan las bacterias de la cavidad oral en las afecciones periodontales necrotizantes o ulcerativas. La GUNA es fuertemente influenciada por las condiciones específicas de cada individuo y los factores predisponentes son fundamentales para la instauración y el progreso de la enfermedad. Al considerar múltiples factores etiológicos, su tratamiento debe ser abordado desde diferentes puntos de acción, la terapéutica debe permitir disminuir la sintomatología intra oral y sistémica y también mitigar los factores asociados al huésped que agravan el cuadro clínico.

Palabras clave: Gingivitis Ulcerosa Necrotizante; Enfermedades de las Encías; Bacterias.

\begin{abstract}
Acute necrotizing ulcerative gingivitis (ANUG) is an infectious disease of the gingival tissue that commonly presents as acute and painful inflammation and/or ulceration. Despite being an infection of bacterial origin, there is still a certain degree of confusion regarding the bacteria associated with it and the role they play in its progress. The aim of this is essay is to establish an epistemological position in relation to the role played by the oral cavity bacteria in necrotizing or ulcerative periodontal conditions. ANUG is strongly influenced by the specific conditions of each individual and predisposing factors are fundamental for the onset and progression of the disease. When considering multiple etiological factors, its treatment must be approached from different points of action, the therapy must allows to reduce intraoral and systemic symptoms and also mitigate the factors associated with the host that aggravate the clinical picture.
\end{abstract}

Keywords: Gingivitis, Necrotizing Ulcerative; Gingival Diseases; Bacteria. 
La gingivitis ulcero necrotizante aguda (GUNA) es una enfermedad infecciosa del tejido gingival. Se presenta comúnmente como una inflamación y/o ulceración aguda y dolorosa, que afecta principalmente la zona de la papila interdental y puede estar acompañada de halitosis, formación de pseudomembranas y sangrado gingival $(1,2)$. Si no es tratada a tiempo, la GUNA puede ocasionar una rápida destrucción del tejido y transformarse en una periodontitis ulcero necrotizante aguda (PUNA) e incluso en un Cancrum oris (Noma), que puede resultar fatal $(3,4)$. La GUNA fue clásicamente diagnosticada en personal militar, sobre todo durante la primera guerra mundial, posiblemente debido a los múltiples factores de riesgos presentes en dicha población. En la actualidad, se considera una enfermedad rara con una prevalencia menor a $1 \%$, que suele ser más común en los países en vías de desarrollo y en pacientes jóvenes en condición de inmunodepresión o con desnutrición severa $(5,6)$.

Existen factores fisiológicos predisponentes que alteran la respuesta inmune del huésped y por lo tanto facilitan la patogenicidad bacteriana de la GUNA. El estrés psicológico, el tabaquismo, el consumo de alcohol, la higiene bucal deficiente, enfermedades gingivales $o$ periodontales preexistentes, las deficiencias nutricionales, y las disfunciones del sistema inmunológico, especialmente la infección por $\mathrm{VIH}$, juegan un papel fundamental en la aparición de la enfermedad $(1,2,7)$.

A pesar de ser una infección de origen bacteriano, aún existe cierto grado de confusión con respecto a las bacterias asociadas con la GUNA y a la función que cumplen en el progreso de la patología (2). En este sentido, el objetivo de este ensayo es establecer una posición epistemológica con relación al papel que juegan las bacterias de la cavidad oral en las afecciones periodontales necrotizantes o ulcerativas, ya que las patologías mediadas por estas bacterias desequilibran la homeostasis del organismo, no solo a nivel local sino a nivel sistémico, pudiendo en algunos casos llegar a destrucciones faciales tipo noma gangrenoso o inclusive la muerte en casos excepcionales.

La identificación del complejo bacteriano asociado a la GUNA ha generado controversia a lo largo de los años, el microbioma de esta patología se ha denominado como una flora variable debido a la complejidad heterogénea de tipos bacterianos presentes. El diagnóstico, por tanto, debe estar basado mayormente en el cuadro clínico, caracterizado por lesiones en forma de cráter a nivel del margen gingival, una historia clínica detallada y en los factores predisponentes asociados al huésped $(1,8)$.
La etiología bacteriana diversa, como se mencionó previamente, cuenta con presencia de espiroquetas y bacterias fusiformes. Con el advenimiento de investigaciones microscópicas, algunos estudios determinaron la presencia en grandes cantidades de Treponema microdentium; mientras que otros, hallaron cepas de Fusobacterium nucleatum, Prevotella intermedia y Selenomonas, los cuales son considerados flora constante en las enfermedades gingivales necrotizantes $(8,9)$.

A partir de biopsias tomadas de pacientes con GUNA, se describieron cuatro zonas de invasión bacteriana, desde la capa más superficial de la lesión hasta la más profunda se encuentran: la capa bacteriana, compuesta por células epiteliales degeneradas, leucocitos, restos celulares y células bacterianas; la zona rica en neutrófilos, que contiene leucocitos, neutrófilos, y espiroquetas; la zona necrótica, compuesta por células desintegradas, espiroquetas y bacterias fusiformes; y por último, la zona de infiltración de espiroquetas, en donde los componentes tisulares se conservan adecuadamente pero se observan espiroquetas de diferentes tamaños $(2,7)$.

Las espiroquetas, como grupo bacteriano han sido ampliamente ligadas a esta condición, estudios específicos basados en cultivos y microscopía han determinado la presencia de gran variedad y altas proporciones de espiroquetas durante este proceso patológico (4). De la misma manera, microrganismos fusiformes y bacteroides han sido cultivados frecuentemente a partir de lesiones de GUNA, sin embargo, un patógeno definitivo que esté ligado a la instauración y progresión de la enfermedad aún no ha sido del todo dilucidado (2). Las modificaciones de tipo cuantitativo, parecen ser la principal diferencia entre una microbiota sana y una microbiota característica de la patología, la más notoria es el incremento en los recuentos de algunos filotipos de Prevotella y Peptostreptococcus. De manera más específica, la Prevotella Intermedia ha sido reconocida como el microrganismo predominante en las lesiones de GUNA $(4,9)$.

La GUNA es considerada una infección bacteriana oportunista, y debido a que la flora bacteriana encontrada durante esta patología también está presente en cantidades considerables en pacientes sanos, se piensa que su aparición está condicionada por una combinación sinérgica de diversas especies bacterianas y un estado inmunológico defectuoso (4).

Resulta entonces indispensable mencionar que los factores predisponentes ya mencionados tienen un rol determinante 
en el inicio y la progresión de la enfermedad. Algunos estudios epidemiológicos han encontrado prevalencias mayores de GUNA en niños de bajo estrato socioeconómico con malnutrición, y en pacientes con $\mathrm{VIH}$ (5). De la misma manera, el estrés psicológico influye de manera positiva en el desarrollo de la condición, durante los períodos de estrés la respuesta inmune se altera, el comportamiento del paciente cambia y hay un aumento de productos esteroideos, cambio en la función de leucocitos y linfocitos, y aumento en los niveles de patógenos periodontales debido a la reducción de la microcirculación gingival y el flujo salival (9).

Así como su etiología, la GUNA requiere un tratamiento con un enfoque multifactorial que involucre una fase aguda, que incluya desbridamiento ultrasónico, oxigenoterapia localizada en las lesiones necróticas, enjuagues con clorhexidina al $0,12 \%$, e incluso el uso de antibióticos sistémicos siendo el metronidazol la droga de elección; se deben tratar también las condiciones predisponentes, las posibles secuelas de la enfermedad e instaurar una fase de mantenimiento que permita evitar las recidivas $(2,7,10)$. Estudios recientes también han demostrado que el uso de fotoquimioterapia como tratamiento adyuvante presenta resultados clínicos y microbiológicamente positivos (8).

El resultado de muchos años de investigación con respecto a las enfermedades periodontales necrotizantes, en especial la GUNA, es la diferenciación de un complejo fusoespiroquetal que ha sido descrito desde el descubrimiento de la patología, no obstante, ningún microorganismo específico ha sido determinado como causante principal de la misma. La GUNA es fuertemente influenciada por las condiciones específicas de cada individuo. Los factores predisponentes previamente mencionados por la literatura, consideramos, son fundamentales para la instauración y el progreso de la enfermedad.

Al considerar múltiples factores etiológicos, el tratamiento de esta patología debe ser abordado desde diferentes puntos de acción, debemos instaurar una terapéutica que permita disminuir la sintomatología intraoral y sistémica pero que también logre mitigar los factores asociados al huésped que agravan el cuadro clínico. Es por esto que debemos prestar especial atención a aquellos pacientes con sistemas inmunológicos deficientes, pacientes con VIH, Leucemia o desnutrición severa, cuyos tratamientos deben tener sin duda una visión multifactorial. La importancia de la salud oral desde el punto de vista de la medicina periodontal como aspecto fundamental en la relación biomedicina / odontología, implica que este tipo de patologías deban ser vistas siempre con una óptica de gravedad necesaria, ya que tiene efectos locales y sistémicos que no pueden ser descuidados por médicos, odontólogos o cuidadores.

Las enfermedades periodontales necrotizantes, dentro de la visión actual de medicina oral, deben ser tratadas con la importancia que requieren puesto que pueden resultar, en los casos más complejos, en la muerte del paciente.

CONFLICTOS DE INTERESES: Los autores no declaran conflictos de interés.

\section{REFERENCIAS}

1. Aaron SL, DeBlois KW. Acute Necrotizing Ulcerative Gingivitis. In: StatPearls [Internet]. Treasure Island (FL): StatPearls Publishing; 2020 [cited 2020 Oct 18]. Available from: http://www.ncbi.nlm.nih.gov/books/NBK562243/

2. Dufty J, Gkranias N, Donos N. Necrotising Ulcerative Gingivitis: A Literature Review. Oral Health Prev Dent. 2017;15(4):321-7.

3. Herrera D, Alonso B, de Arriba L, Santa Cruz I, Serrano C, Sanz M. Acute periodontal lesions. Periodontol 2000. 2014 Jun;65(1):149-77.

4. Bolivar I, Whiteson K, Stadelmann B, Baratti-Mayer D, Gizard Y, Mombelli A, et al. Bacterial Diversity in Oral Samples of Children in Niger with Acute Noma, Acute Necrotizing Gingivitis, and Healthy Controls. Small PLC, editor. PLoS Negl Trop Dis. 2012 Mar 6;6(3): e1556.

5. Hu J, Kent P, Lennon JM, Logan LK. Acute necrotising ulcerative gingivitis in an immunocompromised young adult. BMJ Case Rep. 2015 Sep 16;2015.

6. Dufty J, Gkranias N, Petrie A, McCormick R, Elmer T, Donos $\mathrm{N}$. Prevalence and treatment of necrotizing ulcerative gingivitis (NUG) in the British Armed Forces: a case-control study. Clin Oral Investig. 2017 Jul;21(6):1935-44.

7. Malek R, Gharibi A, Khlil N, Kissa J. Necrotizing Ulcerative Gingivitis. Contemp Clin Dent. 2017 Sep;8(3):496-500.

8. Siddiqui AZ, Vellappally S, Fouad H, Muckarrum SM. Bactericidal and clinical efficacy of photochemotherapy in acute necrotizing ulcerative gingivitis. Photodiagnosis Photodyn Ther. 2020 Mar; 29: 101668.

9. Herrera D, Retamal-Valdes B, Alonso B, Feres M. Acute periodontal lesions (periodontal abscesses and necrotizing periodontal diseases) and endo-periodontal lesions: Dd56II Joint EFP-AAP Workshop. J Clin Periodontol. 2018 Jun; 45: S78-94.

10.Martos J, Ahn Pinto KV, Feijó Miguelis TM, Cavalcanti MC, César Neto JB. Clinical treatment of necrotizing ulcerative gingivitis: a case report with 10-year follow-up. Gen Dent. 2019 Jun;67(3): 62-5. 